\title{
TOBACCO USE AMONG STUDENTS OF RURAL BACKGROUND IN BHOPAL
}

\begin{tabular}{ll} 
Dr. R.K. Gaur* & $\begin{array}{l}\text { Asso. prof, Ananta Institute Of Medical Sciences And Research Centre, } \\
\text { Udaipur, India. }{ }^{*} \text { Corresponding Author }\end{array}$ \\
\hline Dr. Swapnil Jain & Asst Prof, Chirayu Medical College, Bhopal, , India. \\
\hline Dr. DK Shukla & Prof \&HOD, Varun Arjun Medical College, Shahjahanpur, India. \\
\hline
\end{tabular}

ABSTRACT Background: It is well known fact that tobacco kills up to half of its users. 8 million people are killed by the use of tobacco annually. Direct tobacco consumption is responsible for approx seven millions of these deaths and approx 1.2 million deaths due to tobacco use are due to the exposure of non smokers to second hand smoke. The present study was undertaken to study the prevalence of use of tobacco products among rural male students and their knowledge about its injurious effects. Aims and objectives:This study was undertaken to determine the prevalence of tobacco use among students residing in rural background and to assess their knowledge about injurious effects of tobacco products in any form. Material and Methods:The study was undertaken by using a detailed, predesigned questionnaire on the use of tobacco. Results: The prevalence of tobacco smoking was found to be $21 \%$ and smokeless tobacco as $37 \%$ on regular basis. Conclusion: Present study clearly demonstrates the common practice of tobacco consumption among students living in rural background and it is of deep concern. Knowledge about harmful effects of tobacco use certainly have role in restraining the tobacco habit among students.

\section{KEYWORDS : Students, Smoking, Second Hand Smoke, Smokeless Tobacco.}

\section{INTRODUCTION :}

Tobacco use, particularly smoking is a important public health hazard. The main reason for its ubiquity is the addictive drug nicotine present in all forms of tobacco leaf, which is delivered in various amounts by the various methods of tobacco used.

Tobacco smoking is the most important risk factor with the risk rising to 20-30 times in a lifetime of a smoker. ${ }^{2}$ Passive smoking also increases the risk of acquiring lung cancer by $30-50 \%$.

Almost 6 million people die from tobacco use per year, both by direct tobacco use and second hand smoke. About 6 lakh deaths are caused by second hand smoke and of these 1.70 lakh are children. Second hand smoke is the smoke that fills the enclosed spaces, when people burn tobacco products such as cigarettes, beedis and waterpipe etc. It increases the risk of SIDS(sudden infant death syndrome) and may cause various complications of pregnancy including low birth weight babies.

In 2012, there were about 1.1 billion smokers world wide, with over $80 \%$ every day smoker. ${ }^{3}$ By 2020 , this number has increased to 7.5 million contributing for approximately $10 \%$ of all mortalities.

Smoking play an important role in causing and aggravating the carcinoma of many organs including lungs, urinary bladder etc. In lower middle income countries the incidence of smoking is very common when it is compared with upper income countries.. An important cause of disease, death and disability is the frequent and regular consumption of tobacco. Magnitude of the tobacco problem can be measured by estimating the prevalence of tobacco use in that population. ${ }^{4}$

All forms of tobacco are injurious to health and there is no safe level of the dose of tobacco. Cigarette smoking is the commonest practice of tobacco consumption, other forms of tobacco includes smokeless tobacco. Smokeless tobacco use is highly addictive and injurious to health. It contains many cancer causing toxins and its use enhances the chances of carcinoma of the head, neck, throat, esophagus and oral cavity and also various dental diseases. 5
Benowitz et $a{ }^{6}$ compared the effect of smokeless tobacco, cigarettes and nicotine gums and demonstrated that all type of tobacco use results in hypertension and tachycardia after comparing the effect of smokeless tobacco, cigarettes and nicotine gums.

Researches undertaken in many developed nations have shown that there are few triggering factors, which may cause initiation of habit of practicing tobacco use. These triggering factors include effects of tobacco advertisements, smoking habits of parents or other adults in the family, pressure of peer group and also insufficient or lack of information about harmful effects of tobacco consumption.

The world adopted tobacco use in the form of smoking, chewing and snuffing (finely powdered tobacco leaves)

In India, as per a WHO report, percentage of men use some form of tobacco is approximately $65 \%$. Of which about $35 \%$ smokes and about $22 \%$ use smokeless tobacco while $8 \%$ practices both. In India, about $3 \%$ of women smoke, while $47 \%$ of men and about $12 \%$ of women smoke globally.

The aim of the this study was to find out the dispersal of tobacco use among rural students and their knowledge about injurious effects of tobacco consumption. They are in the vulnerable age group when their lifestyle patterns changes and affect their life.

\section{MATERIAL AND METHOD:}

Present study was undertaken in a defined male population residing in a village of Tehsil Huzur, located approximately 20 Km from Chirayu Medical college ,Bhopal, Madhya Pradesh. Male students taken for study belonged to the age group of 16 years to 25 years. It covered six month period from Jul 2019 to Dec2019.

Before commencing the study, sample size was taken in to account by considering the criteria incorporated in the book 'sample size determination in Health'. ${ }^{8}$ A complete list of all male students was prepared living in that village. The sample of 314 subjects was drawn from this list (the study population), using random number tables. The required sample was selected from different age categories using stratified random sampling method. 
All of them were given a detailed predesigned questionnaire on tobacco use. The questionnaire in it was designed following the guidelines and directives given in various text books. ${ }^{9}$ The subjects were asked to fill up the questionnaire, which was self administered anonymously so as to reduce under-reporting of tobacco use.

questionnaire was based on the types tobacco use, its frequency, and information about the injurious effects of tobacco use.

Pilot study was conducted on 20 subjects, selected randomly with a view to ascertain the dispersal of tobacco consumption in the community under study and during this pilot study, questionnaire was tested, standardized and validated so as to ensure high content criteria and validity.

They were asked about their smoking habit and use of tobacco in forms other than smoking (smokeless tobacco) viz. chewing, snuffing etc.

They were also asked details like brand of smoking (beedis/ cigarettes), number of days of smoking in a week, no of cigarettes or beedis, they usually smoked on the day of smoking and period of smoking. Period of recall was kept as 'past one year'. Subjects who never smoked were kept in category of 'non smokers' and the individuals not smoked in past one year but used to smoke earlier were kept in the category of 'ex smokers'. Occasional smokers, were those who used to smoke not more than once or twice a week. Regular smokers, were having habit of smoking daily.

The average no of cigarettes or beedis per day were computed as (no of days of smoking in a week $x$ no of cigarettes or beedis smoked on the day of smoking divided by 7 ). This procedure of assessing smoking tobacco was taken from a survey (AFMRC report 1994). ${ }^{10}$

For assessing consumption of smokeless tobacco, subjects were first asked about the details of their tobacco item other than smoking viz. tobacco chewing in pan, Khainee, snuff, gutka etc. they were also asked about number of days of smokeless tobacco use in a week, and the period of smokeless tobacco use. Period of recall was kept as 'past one year'. Subjects who never used were kept in category of 'non smokeless tobacco users' and individuals used to have earlier but not consuming for past one year, were kept in the category of 'ex smokeless tobacco users'.

Besides this, it was also included in questionnaire about their knowledge and awareness regarding serious consequences and ill effects of tobacco use in all forms.

\section{RESULTS :}

Out of the 201 subjects studied in this study, (64\%) were nonsmokers. Out of remaining $36 \%$, there were $66(21 \%)$ regularly smoking cigarettes., out of which $53(17 \%)$ were smoking tobacco for past 5 years and $13(4 \%)$ were having habit of smoking for $>5$ years. 28 (9\%) were smoking occasionally. 19 ( $6 \%$ ) were ex-smokers,

It was also observed that, $37 \%$ were smokeless tobacco users and maximum subjects (19\%) were using tobacco in form of Khaini ( Mixture of dry tobacco and lime powder) which is very popular and common in villages of Madhya Pradesh. 9\% were fond of paan form using tobacco in it. $8 \%$ were consuming it in form of Gutka and $1 \%$ were using it as snuffing.

$160(51 \%)$ subjects never used tobacco in smokeless form and among 116 (37\%) users of smokeless tobacco, 82 (26\%) were consuming it for past five years and $34(11 \%)$ were consuming it for over five years. $22(7 \%)$ were occasional user whilel6 $(5 \%)$ were ex smokeless tobacco user.
Adequate knowledge of injurious effects and serious consequences of tobacco consumption in any nature, was tested and it was observed that among smokers $(21 \%$ regular + 9\% occasional smokers) Only 41 (13\%) were having adequate knowledge while among smokeless tobacco users (37\% regular $+22 \%$ occasional users) only $34(11 \%)$ were conscious of the injurious complications of tobacco consumption.

TABLE 1,

Prevalence of smoking

\begin{tabular}{|c|c|c|}
\hline Habit of Smoking & Number of users & Percentage \\
\hline Non Smoker & 201 & $64.0 \%$ \\
\hline Ex smoker & 19 & $06.0 \%$ \\
\hline Occasional & 28 & $09.0 \%$ \\
\hline Regular- $<5$ years & 53 & $17.0 \%$ \\
\hline Regular $>5$ years & 13 & $4.0 \%$ \\
\hline Total & 314 & $100 \%$ \\
\hline
\end{tabular}

\section{TABLE 2}

Different forms of smokeless tobacco use

\begin{tabular}{|c|c|c|}
\hline Forms of smokeless Tobacco & No of users & Percentage \\
\hline Gutka & 25 & $08.0 \%$ \\
\hline Khainee & 60 & $19.0 \%$ \\
\hline Chewing in paan & 28 & $09.0 \%$ \\
\hline Snuff & 03 & $01.0 \%$ \\
\hline Total & 116 & $37 \%$ \\
\hline
\end{tabular}

Table-3 Prevalence of smokeless tobacco users

\begin{tabular}{|c|c|c|}
\hline Smokeless Tobacco Users & Number of users & Percentage \\
\hline Never used & 160 & $51.0 \%$ \\
\hline Ex users & 16 & $05.0 \%$ \\
\hline Occasional users & 22 & $07.0 \%$ \\
\hline Regular- $<$ 5years & 82 & $26.0 \%$ \\
\hline Regular $>5$ years & 34 & $11.0 \% \%$ \\
\hline Total & 314 & $100 \%$ \\
\hline
\end{tabular}

Table-4 knowledge about injurious effects of tobacco use

\begin{tabular}{|c|c|c|}
\hline $\begin{array}{c}\text { Adequate } \\
\text { knowledge about } \\
\text { injurious effects of } \\
\text { tobacco use }\end{array}$ & $\begin{array}{c}\text { smokers } \\
\text { (regular } \\
\text { +occasional) }\end{array}$ & $\begin{array}{c}\text { Smokeless } \\
\text { Tobacco users } \\
\text { regular } \\
\text { +Occasional) }\end{array}$ \\
\hline Present & $41(13 \%)$ & $34(11.0 \%)$ \\
\hline Not Present & $53(17 \%)$ & $104(33.0 \%)$ \\
\hline Total & $94(30.0 \%)$ & $138(44.0 \%)$ \\
\hline
\end{tabular}

\section{DISCUSSION :}

It was observed that $21 \%$ were regular smokers and $9 \%$ were occasional smokers. This finding was also observed by a WHO report ${ }^{7}$ that globally, $47 \%$ men are tobacco smokers. The observations of this study that $37 \%$ subjects were consuming tobacco in smokeless form, slightly higher than the observation of a WHO expert group report ${ }^{11}$ that in India, 27\% of men are using tobacco in smokeless form. It is estimated that in India, about $65 \%$ of all men use tobacco in some form. (About 35\% smoking, 22\% smokeless tobacco, 8\% both) ${ }^{12}$.

It was also found that majority of the individuals were smoking (17\%) and using tobacco in smokeless forms(26\%) for less than five years. Besides this, the present study also revealed that majority of the smokers (21\%) and non smokers (37\%) were not having adequate knowledge about serious consequences and injurious complications of tobacco use in its all forms.

The most important aspect has been the practice of methodology which target the influences of society on smoking habit. Evans ${ }^{13}$, categorized several factors influencing the individual to initiate use of tobacco at early or later stage of life. These were smoking habit of parents or any adult in the family, peer group pressure and the marketing media. 
McAlister and others ${ }^{14,15}$ developed the methodology and suggested the role of peer group leaders as educators, motivators to coordinate activities to enhance the social obligations of abstaining from smoking and encouraging others too.

Keeping in view, the serious health hazards of tobacco consumption and the finding of this study that a considerable number of subjects were tobacco consumers is highly concerning and needs to be viewed seriously. Hence, it is required to educate and motivate the society and to users to give up the practice of tobacco use.

Hence all possible measures should be implemented to eliminate tobacco use, particularly smoking and for this, all medical and administrative authorities should provide assistance to all users of tobacco to stop the consumption of tobacco in all forms and not to adopt the habit Of tobacco consumption.

Various Studies on this aspect have demonstrated that most people understand the specific health risks of tobacco consumtion and want to quit. Professional support and proven cessation medications can more than double a tobacco user's chance of successful quitting. ${ }^{16}$

\section{RECOMMENDATION:}

The present study has limited itself to estimating prevalence and knowledge about the injurious effects on the student's tobacco habit. Significant associated factors such as tobacco marketing media, easily availability of tobacco products , pressure of peer group, role of parents etc have not been taken in to account in this study. It is strongly recommended that long term national policies on tobacco marketing, sale, prices, smoke free areas should be made to discourage habit of tobacco consumption.

Besides above legal action plans, for distracting smokers and encouraging them to quite smoking other methods can also be used viz. Large pictorial or graphic health warnings and meaningful messages. It will also protect the non smokers by not allowing others to smoke inside the premises of home and public places. Studies have shown that pictorial warnings significantly increase people's consciousness of the harms from tobacco consumption. Besides this, tobacco taxes are the most cost effective way to reduce tobacco use.

\section{REFERENCES :}

1. International programme on chemical safety (IPCS). Geneva,WHO, 1999, 149 pp.

2. Viscusi et al, Risk beliefs and smoking behavior, economic inquiry,vol.46, No l, Jan2008

3. WHO, Global status report on non communicable disease, 2014.

4. Guidelines for controlling and monitoring the tobacco epidemic (Monograph). WHO, Geneva 1998.

5. Myers et al, Cigarette smoking among adolescents with alcohol and otherdrug use problems, Alcohol research, vol 29,No.3

6. Benowitz N.L.et al, Nicotine absorption and cardiovascular effects with smoke less tobacco use. Clinical pharmaco.therapy,44:23-8

7. WHO expert committee report, Tpbacco or health: a global report, JIMA,97 : 377-84

8. Lwangaet al, Sample size determination in health studies: a practical manual.1991;p-80

9. Rose et al, cardio vascular survey methods. WHO monograph series.Geneva: WHO1982;561:78

10. Bhalwar R.et al, Study of prevalence and epidemiological distribution of certain coronary risk factors among service personnal, AFMRC project no.1876191.New Delhi: DGAFMS,1994.

11. World hypertension League, Alcohol and hypertension,implication for management. Bulletin, 69: 377-82

12. Tobacco or health: A global status report (Monograph). WHO. Geneva, 1997.

13. Evans RI. Deterring the onset of smoking : Knowledge of immediate physiological effects and coping with peer pres-sure, media pressure and parent modeling. Journal of Applied Social Psychology 1978.8: 126-35.

14. McAllister A, Perry C, Maccoby N. Adolescent smoking: Onset and preventing. Paediatrics 1979,643:5650-8.

15. Botvin GJ, Eng A. A. comprehensive school based smoking prevention programme. J Sch Health 1980, 50:209-13.

16. Nichols Richardsons, Smoking prevention, J. family and consumer sciences, vol.94, No.4, Nov 2002 